ZalącZnils

DOI 10.21697/zk.2021.8.01

\title{
PRAKTYKOWAĆ MEDIA/PRAKTYKOWAĆ SIEBIE... O DOŚWIADCZANIU PRZESTRZENI PÓŹNEJ NOWOCZESNOŚCI
}

Karina BanaszkieWicz

Instytut Nauk o Kulturze UŚ

Culture Studies Institute

University of Silesia in Katowice

karina.tv@gazeta.pl

ORCID: 0000-0003-3796-6602

Zaawansowana globalizacja uczyniła narzędziami kulturowej zmiany kod digitalny, komputer oraz Internet. Media generacji 2.0, 3.0 i 4.0 wytwarzają i rozpowszechniają obrazy, sztuczne zdarzenia, obiekty. Wraz z kolejnymi formami medialnymi pojawiają się kolejne schematy, które kształtują sposoby widzenia i dominują w procesach projektowania i komunikacji. Liczba oferowanych przez kulturę widzialności czyni matryce przekaźników reżimami (dla) oka i cielesnego doświadczenia rzeczywistości. Poczucie realnego jest modelowane coraz częściej przez technikę (strumienie TV, cyberprzepływy, przestrzenie wpisane w przekazy) oraz same formy późnej audiowizualności (symulacje, hybrydy, topie onto-ontologiczne). Istotne stają się dwie kwestie. Pierwsza to dostęp do rzeczywistości oferowany przez „obrazy” (satelity, hełm HDMI, okulary bojowe etc.). Druga to pytanie, jak zobaczyć świat spoza matryc mediów i matryc widzialności.

Przekaźniki - a ściślej wielomedialne platformy komunikacyjne dystrybuują nie tylko schematy widzenia, ale i prawo do patrzenia (extranet, listy znajomych, dostęp do archiwów, bibliotek, profile konsumentów gromadzone przez Google, MS etc.). Nadmiar sztucznych form i przestrzeni kieruje zaś uwagę na uczestnictwo i uczestników kultury: jednostki i wspólnoty (realne, wyobrażone, wirtualne). Każe myśleć o tożsamości oraz ludzkich aktywnościach przenoszonych do cyfrowej mediasfery. Tekst podejmuje lekturę praktyk tożsamościowych jednostki - jej udziału w kulturze. Jednostkową spójność i sposoby jej budowania przez podmiot wpisuje w konteksty immaterialnej rzeczowości, troski o siebie, potrzeby 
więzi i integracji z Innym. Omawia zatem techniki rozwiniętej audiowizji (ich matryce i przestrzenie) oraz realizowane przy ich udziale tożsamości, procesy ich formowania i negocjowania z innymi (w zakresie treści indywidualnych i grupowych, a także treści uniwersalnych np. człowieczeństwa). Praktyki tożsamościowe są lokowane w ramach przepływów i transmisji danych, baniek informacyjnych, heterotopii oraz obecnych tam figur (legitymizujących instytucje państwa, figur oporu i projektów nowego ładu społecznego). Tekst czyta również tożsamość w kluczu os oby i maski. Analizuje taktyki użytkownika, za pomocą których artykułuje on swoje trwanie w społecznościach (cyber)wirtualnych (np. w postaci awatarów, ników, tożsamości wielokrotnych). Tropi również tryby wizualizacji danych: profile użytkownika, metryczne identyfikatory, kartoteki, algorytmy wyboru, historie wyszukiwań, archiwa publikowanych zdjęć... - słowem: instytucjonalne strategie nadzoru.

Ponowoczesność przyniosła nadmiar przestrzeni wytwarzanych przez maszyny. To już nie wizja „wieku przestrzeni” zapowiadanego przez Michela Foucault ${ }^{1}$, lecz codzienność. Życie euroatlantyckich społeczności wymiaruje dziś bowiem digitalizacja: nadprodukcja e-obrazów (gazet, fotografii, kina, telewizji), Internetu, bazujące na nim media i postmedia, widzialności VR, a także mechatroniczne protezy rozszerzające możliwości organicznego ciała, eugenika, temy, sztuczna inteligencja - słowem: cyfrowo-falowe technologie, wielomedialna komunikacja i hybrydowe uniwersa. Tekst omawia przestrzenności wytwarzane przy udziale przekaźników zaawansowanej audiowizji - a dokładniej: sposoby korzystania z przestrzeni źródłowo-technicznych ze szczególnym uwzględnieniem budowania w oparciu o nie tożsamości i praktyk tożsamościowych. Tekst kreśli kolejno generacje przekaźników z typowym dla każdego schematem (re)prezentacji przestrzeni na czele, z oferowanymi użytkownikowi możliwościami (auto)kreacji i prawem do patrzenia, otwierając - kwestie udziału mediów w przechodzeniu gospodarki postfordowskiej w fazę zarządzania algorytmami rozwoju. Przywołane wyżej zagadnienia szkicują pole refleksji powstające wokół współczesnych środków komunikacji. Dokładniej: sygnują jego granice za pomocą przestrzeni (i przestrzenności) tworzonych przez człowieka

M. Foucault, Inne przestrzenie, tłum. A. Rejniak-Majewska, „Teksty Drugie” 2005, nr 6(96), s. 117-125. 
w trakcie użytkowania mediów (i form medialnych). Czytaj: przy udziale maszyn - aktywności i treści, które za pomocą maszyn są kreowane, powtarzane i rozpowszechniane.

Myślenie o przekaźnikach zaawansowanej cyfryzacji w kategoriach ludzkiego narzędzia implikuje pytanie o proksemikę - dyktowane użytkownikowi zachowania, tryby artykułowania przestrzeni i rzeczywistości, ich waloryzacje, sposób dystrybuowania treści. Otwiera istotne dla kultury i tożsamości kwestie. Należą do nich typowe dla człowieka taksonomie, w jakich porządkuje świat. Dotyczy to przestrzeni i doświadczanych przy ich udziale przestrzenności: miejsc i krajobrazów, również tych fundowanych siłami techniki. Coraz częściej to właśnie one stają się polami aktywności wspólnot realnych i wyobrażonych, a także wirtualnych. W konsekwencji stały się elementami wyobrażeń zbiorowych. Pozwalają zachować spójność jednostce i wspólnocie (czy szerzej społeczności), budować tożsamość i negocjować ją z innymi². Jako treści kulturowe służą integracji grup i zbiorowości. Wtórnie modelują też odczuwanie przestrzeni fizycznych. Dziś bowiem i formy medialne, i przestrzenie działania oferowane przez przekaźniki cechuje wielozmysłowość - zdolne są one angażować nie tylko ucho i oko, ale także dotyk, kinestezję, węch użytkownika, wkraczać w przestrzeń jego domu, parku, miasta.

Toteż przyjęta w artykule perspektywa koncentruje uwagę na relacjach użytkownika i „komputera” (czytaj: użytkownika i mediów rozwiniętej audiowizji). Owocują one, opisywanym prze Henriego Lefebvre’a, społecznym i kulturowym wytwarzaniem przestrzeni: budowaniem jej materialnych i immaterialnych krajobrazów oraz przedstawień, a wreszcie jej kreacją $\mathrm{w}$ antropologicznych przestrzeniach reprezentacji ${ }^{3} \mathrm{w}$ postaci ideacji i wzorów obejmujących świat kultury kontekstu. W wymiarze uniwersalnym przestrzeń staje się warunkiem koniecznym, by człowiek rozpoznał różnicę między sobą a otoczeniem, by konstytuował świat, a zewnętrze stało się dla niego widzialne jako świat - bowiem tam, gdzie nie ma doświadczenia przestrzeni, nie ma też świata ${ }^{4}$. Na planie empirii - kiedy mowa o zapośredniczonym

2 Ch. Taylor, Źródła podmiotowości. Narodziny tożsamości nowoczesnej, tłum. M. Gruszczyński, Warszawa 2001, s. 18 i nn.

3 H. Lefebvre, Production de l'espace, Paris 2000, ss. 8-9, 32-33.

4 K. Banaszkiewicz, Nikt nie rodzi się telewidzem, Kraków 2011, s. 125 i nn. 
przez technikę uczestnictwie w kulturze - chodzi zatem o jednostkowe i grupowe praktykowanie przestrzeni sztucznych i hybrydowych. Liczy się ich produkcja i mapowanie, wizytowanie i zamieszkiwanie, a także sposoby ich doświadczania kolejno w roli przestrzenności: krajobrazu, miejsca i świata.

Inny wymiar zależności człowieka i techniki przynosi „komputer” postawiony w roli narzędzia umożliwiającego jednostce konstruowanie podmiotowości i zarządzanie sobą, w tym poznanie. Uczenie się w celu adaptowania się do warunków zewnętrznych w ujęciu podmiotowym staje się troską o siebie. Jej rewers stanowi troska sensu stricto. Oznacza ona samorealizację wedle subiektywnego programu: odczucia potrzeb. Nakierowana do wewnątrz i na to, co zewnętrze, troska o siebie postępuje wedle dwóch przeciwnie kierowanych wektorów. Ich relacja wyznacza pole kształtowania się podmiotu, zaś wynikające z różnicy między nimi napięcia wyznaczają dynamikę tego pola i określają treści kultury, które pozostają w nim niejawne lub niewypowiadalne, widzialne, naoczne i słyszalne, a także te, które potencjalnie mogą się w nim pojawić. Dynamika ludzkiej troski o siebie wraz z treściami pola kulturowego warunkują, jakim można w danym polu stać się podmiotem, np. artystą, kobietą, szaleńcem, oraz wskazują środki, które temu służą. Wyznaczane wedle wektorów działania i zachowania subwersje troski o siebie, wiążą za sprawą aktywności podmiotu zatem dwie praktyki. Pierwsza obejmuje budowanie tożsamości (np. chrześcijanina, zwolennika determinizmu technicznego) na drodze uwewnętrznienia reguł kontekstu kulturowego i społecznego (np. nauk Nowego Testamentu i Kościoła, prawd technologicznej gnozy). Druga zaś obejmuje dążenie jednostki do spełnienia i budowanie podmiotowej tożsamości wedle wewnętrznego jednostkowego porządku, indywidualnie pojętego szczęścia. Obie te praktyki Michel Foucault nazywa te ch nik a mi siebi $e^{5}$. Są one równie ważne, co technologie i maszyny wybierane przez uczestników kultury ponowoczesnej na narzędzia reprezentowania i kreacji siebie. Dyskursy przestrzeni i sposoby jej cielesnego praktykowania pozostają ekstensją, realizacjami właśnie niezbywalnej troski o siebie towarzyszącej człowiekowi. Dotyczy to również form medialnych: materialnych i immaterialnych obrazów, obiektów, zdarzeń. Dlatego też będę

M. Foucault, Techniki siebie, tłum. D. Leszczyński, L. Rasiński, [w:] idem, Filozofia, historia, polityka. Wybór pism, Warszawa-Wrocław 2000, s. 247-249. 
starała się spojrzeć na produkowane przez media formy - ich przestrzenie, krajobrazy i miejsca - jako na rzeczy i narracje, z których uczestnik późnej globalizacji korzysta z zamiarem przystosowania się do środowiska, grupy etc. lub celem realizacji subiektywnie zakrojonego szczęścia.

Immaterialna rzeczowość, podobnie jak przed nią materialne tworzywa i wytwarzane z nich przedmioty, manifestuje tożsamość kulturową jednostki. Niezmiennie chodzi o aktualizowanie i waloryzowanie treści składających się na jej autoobraz, dzielony przez podmiot z pozostałymi członkami wspólnoty. W perspektywie autoobrazu wspólnota odmawia lub przyznaje jednostkom status uczestnika, członka, s woja ka. Jednostka natomiast buduje swą jedność w planach akcydentalnym, grupowym, uniwersalnym. Dziś coraz częściej praktyki identyfikacji i autoidentyfikacji członków zbiorowości (społeczności, narodu, wspólnoty realnej, wyobrażonej czy wirtualnej) realizowane są przy użyciu wielomedialnych platform komunikacyjnych. Tym samym praktykowanie siebie rozszerzone zostaje o możliwości zaawansowanej cyfryzacji i jej przestrzenie, w których podmiot podlega licznym wizualizacjom i identyfikacji. Użytkownik współczesnej mediasfery buduje swoje autoobrazy i równocześnie podlega zinstytucjonalizowanym formułom wizualizowania, gromadzenia danych, zapisu. I personalnie, i instytucjonalnie wytwarzane notacje podmiotu powstają wedle parametrów, jakie wypracowała globalizacja w celu katalogowania i jakimi operuje aktualnie technika. Współcześnie, niczym w dobie pierwszej nowoczesności, uczestnik kultury jest weryfikowany na bazie personalizowanych matematycznie danych: numerów IP komputera, telefonu czy kamery, swoich aktywności, numeru karty kredytowej, odcisku palca czy źrenicy oka. Zyskuje (cyber)tożsamość, która w postaci zapisu technicznych metryzacji podlega urynkowieniu (m.in. monetyzacji) i instytucjonalizacji, archiwizacji i kontroli Google, MS, policji, służb granicznych, banków, administratora portalu etc. Poprzez udział w cyberprzestrzeni sam również buduje własne, spersonalizowane tożsamości, zmienia je, mnoży i duplikuje w postaci nicków i awatarów (np. Second Life’u, Cyber Academii, gier wideo). W uproszczeniu, po stronie instytucji i rynku stoją strategie (re) konstruowania tożsamości netizena i kontroli, zaś po stronie użytkownika mediów taktyki budowania tożsamości, jej operacyjnego wykorzystania w trosce o siebie (tj. zgodnie z własnym programem szczęśliwego życia). Subwersywne korzystanie z możliwości maszyn 
staje się fundamentem dominującego wid zenia i kont rw id zenia (które ma charakter alternatywny, równoległy, podporządkowany, wykluczony z dyskursu dominującego). I nie idzie tu o determinizm techniczny czy indeterminizm, lecz o inwentarz kultury. O należące do niej przedmioty, modelowane przez nie zachowania oraz znaczenia, wartości, idee - treści, w tym obrazy i autoobrazy służące ludziom do identyfikacji i autoidentyfikacji w dostępnych im przestrzeniach produkowanych mocami techniki.

\section{O PRAKTYKOWANIU MEDIÓW}

Kod digitalny to niejawne tworzywo przestrzeni numeryzowanych i numerycznych, które powstają w polu kultury globalizowanej przy udziale mediów. Wsparty opcjami oprogramowania przekaźników, regułami operacyjnymi budowania tego, co środkami techniki do pokazania możliwe i niemożliwe, oferuje on i limituje dostępne schematy przestrzeni, działając niczym kolejny porządek reprezentacji - matryca wizualności. Jak zobaczyć świat za pomocą matryc: satelity, komputera, smartfona, hełmu HDMI czy biogatu? Kwestia ta, wielokroć podnoszona przez teoretyków wizualności, to pytanie o upowszechniany w kulturze przez narzędzia cyfrowe dominujący porządek reprezentacji i reżi m wi zualny. Media i postmedia mają wszak swoją historię. Za sprawą Internetu od 1992 roku wdrażano model komunikacji 2.0. Schemat „wszędzie, wszyscy wiedzą wszystko” obiecywał nieograniczone możliwości wymiany wiadomości, wiedzy, darów. Umożliwiał lekturę oraz „kładzenie” informacji na stronie lub na „scenie programu" (współtworzenia hipertekstu lub uniwersum) - dawał użytkownikowi jednocześnie gestie nadawcy i odbiorcy. Mettre en page - mettre en scéne - mise ouevre à fair ${ }^{6}$ to gesty powołujące do życia sztuczne krajobrazy, miejsca, światy o różnym stopniu trwałości. Wytwarzane, przedstawiane i anektowane przez media przestrzenie stają się istotnym dyskursem zmiany kulturowej. W tym zakresie media 2.0 zaproponowały zarówno obrazy rzeczywistości i światy sztuczne, jak i procedury ich tworzenia oraz udział w życiu powstających tam zbiorowości.

${ }^{6}$ Mettre-en-page - położyć na stronie, np. internetowej; mettre-en-scéne-położyć na scenie, wystawić na widzenie np. w postaci filmu, wyreżyserować; mettre ouevr à fair - dać, wystawić do zrobienia, np. artefakt w postaci instalacji interaktywnej. 
Kolejne przestrzenie mediów wyznaczyła konwergencja. Równoprawny dostęp do Internetu z komputera czy panelu lodówki wymusił opcje wzajemnych połączeń między samymi urządzeniami, a także publikowaną w nich zawartością. Linki, odsyłacze itd. wzbogaciły struktury mediów 2.0. Za sprawą „drzwi” Internetu stały się „mostami” wiążącymi przekaźniki, bibliografią w działaniu. Cross media wdrożyły tryb lektury synergicznej. Użytkownik mediów 3.0 rozpoczął spotkanie z narracją za sprawą dowolnego medium i w dowolnej sekwencji opowieści, którą sam kompletował jako patchwork. Krok następny należał do symulacji. Poprzedziły ją laparoskopowa chirurgia, która każe lekarzowi prowadzić zabieg przy udziale monitora, działać i śledzić postępy za pośrednictwem mechatronicznego skalpela nie w ciele pacjenta, lecz na obrazie, e-bankowość, kryptowaluty czy opcje pozwalające spieniężyć zasoby zgromadzone w świecie gry. Symulacja otworzyła nowy poziom wiązania życia i cyfrowej wirtualności. Jakościową zmianę w tym zakresie przyniósł rynek gier. Za pomocą narracji Pokemony Go koreańska firma - właśnie pod szyldem gry wideo - zaoferowała spacer z kultowymi bohaterami japońskiej animy, filmów i telewizyjnych kreskówek. Cyfrowe postaci stały się dla grającego nie tylko widzialne w przestrzeni fizycznej, ale i reagowały na jego działania, a nawet by go przechytrzyć, podejmowały działania (stawały się interaktywne). Gra zaoferowała pozbawione naocznych granic współbycie z cyfrowymi obiektami w przestrzeni ulicy, parku itp. Symulacja udostępniła sytuacyjne stopienie przestrzeni o różnym statusie bytowym - ściślej: złożenie realnego i sztucznego. Postać Pokemona program czyni naoczną na czas gry, po jej zakończeniu, jak na symulację przystało, wirtualnie nadal trwa ona (jako układ cyfr) niedostępna dla zmysłów jako postać pozbawiona chwilowo przywileju widzialności i obecności, lecz gotowa do kolejnej aktualizacji obecności, np. spaceru z użytkownikiem medium generacji 4.0. Nakładające się na siebie podczas trwania rozgrywki fizyczne miejsce i przepływy cyfrowych danych/obiektów - Pokemonów - stają się hybrydą onto-ontologiczną. Niczym widok uzyskiwany dzięki okularom bojowym są przykładem przestrzeni powiększonej’, poszerzonej o sztuczne augmenty. Ta sytuacyjnie stapia przestrzeń dostępną zmysłowo i obraz sztuczny na nią projektowany przez smartfona, gdy mowa

7 L. Manovich, Poetyka powiększonej przestrzeni, tłum. A. Nacher, Miasto sztukisztuka miasta, red. E. Rewers, Kraków 2010, s. 596-628. 
o Pokemonach, lub przez mikrokamery wojskowych okularów przekazujących żołnierzowi obraz satelitarny ulicy pozostającej w danej chwili poza zasięgiem jego wzroku. Miejsce fizyczne poddane hybrydyzacji za sprawą przepływu danych/form widzialnych zostaje powiększone o projektowane obrazy i sztuczne obiekty. Zyskuje strukturę palimpsestu, w którym na rzeczywistość nakładane są warstwy sztucznej widzialności. W przestrzeń fizyczną włączane są: obrazy (okulary bojowe), obiekty (Pokemony) lub wielozmysłowe zdarzenia medialne - VR (program treningu podawany z hełmu HDMI). Zmiana właściwości miejsca wzbogacanego o augmenty i warstwy generowane technologicznie, podobnie jak sytuacyjnie nabywane przez nie własności heterotopii czy nabywana funkcjonalność typowa dla przestrzeni atopicznych, wymagają osobnego omówienia - nie sposób opisać je wyczerpująco w ramach krótkiego szkicu.

Przywołane matryce mediów przekraczają potencjalną liczbą możliwych realizacji ludzkiej zdolności percepcji, lecz nadal ogranicza je oprogramowanie maszyny. Wciąż zatem schematy widzenia prowadzą do porządków reprezentacji objętych opcjami urządzenia i do konwencji kultury. Aktualna siatka mediów 2.0, 3.0, 4.0 i przestrzeni wiązanych ze sobą Internetem każą zastanowić się nad cyfryzacją jako reżimem widzenia, zaś rosnąca liczba „komputerów” nad kolonizacją wizualną, jakiej podlega świat życia codziennego (o którym mówi Jürgen Habermas).

Komputer i projektowanie obiektowe doby numerycznej wyrosły z reguł perspektywy renesansowej. Digitalna symulacja zniosła jednak środkowoeuropejski schemat budowania przestrzeni - siatkę linii biegnących od przedmiotów do jednego centrum, do wszystkowidzącego oka. Obraz cyfrowy realizowany wedle perspektywy zbieżnej to już nie wymóg maszyny (model obiektywu kamery), ale wybór projektanta i konwencja kultury. Wypada zatem ponownie przyjrzeć się kwestii reżi mów oka. Należy zadać pytanie o to, jak postrzegamy świat spoza medialnych matryc i kolonizujących widzenie kreacji - cyfrowych przestrzeni, które stają się coraz częściej elementami tożsamości indywidualnej i zbiorowej. Trzeba zapytać: czy „komputer” zdoła dać kolejny wzór doświadczania świata, powszechny i uważany za naturalny porządek percepcji? Czy otworzy autonomiczną kulturę wizualną i zmieni przestrzenie reprezentacji charakterystyczne dla człowieka? To istotne problemy, gdy chodzi o zmiany w kulturze wywoływane 
przez dominacje narzędzia („komputera”), tworzywa (immaterii) i rzeczy (wirtualnych obiektów i przestrzeni).

\section{O PRAKTYKOWANIU PRZESTRZENI}

Rozwinięta audiowizja oferuje dyskursy przestrzeni 1.0, 2.0, 3.0 i 4.0, modeluje zachowania konieczne i możliwe użytkowników, a tym samym określa cielesne praktykowanie przestrzeni ${ }^{8}$ sztucznych, dostępnych uczestnikom kultury w roli świata (a z czasem jako światów alternatywnych). Krajobrazy i miejsca, także te o cyfrowym rodowodzie, to zatem wciąż media kultury. Niosą scenariusz możliwych i niemożliwych trybów życia $\mathrm{i}$ istnienia, a jednocześnie stanowią ich notacje. Sztuczne uniwersa zyskują status Heideggerowskiej pr zestrzen ności za sprawą człowieka'. Mowa o konstytuowaniu przestrzeni medialnych, a więc wytwarzanych i publikowanych przy udziale analogowej z ducha techniki (np. fotochemicznej lub technologii numerycznej), a internalizowanych przez uczestników kultury. Przestrzenie te są przez nich rozpoznawane, nasycane treściami, włączane w życie i wykorzystywane do poznania rzeczywistości, a także do jej przedstawiania kreacji. Przestrzenie sztuczne są zatem waloryzowane przez jednostkę oraz zbiorowość i funkcjonalizowane jako treści w ramach ich własnego autoobrazu (jednostkowego i grupowego). Każdy z zakresów naturalizacji przestrzeni, a także form medialnych, winien stać się przedmiotem szczegółowej analizy.

Topie przestrzeni medialnych i fizycznych w drodze udziału komunikacji stają się automatycznie treściami ponowoczesnej tożsamości. Służą jednostce do budowania własnego bycia-w-ś wiecie społecznym, kulturze, przyrodzie. Pozwalają negocjować z innymi własny wizerunek, osobę i warunki partycypacji w społeczności ${ }^{10}$. Wspólnotom wyobrażonym i ich członkom ${ }^{11}$ doba globalizacji cyfrowej (i algorytmicznej) oferuje nowe terytoria działania i trwania. W efekcie legitymizuje ich obecność i udział w kulturze.

8 M. Certeau, Wynaleźć codzienność. Sztuki działania, tłum. K. Thiel-Jańczuk, Kraków 2008, s. 115-133.

9 M. Heidegger, Bycie i czas, tłum. B. Baran, Warszawa 2004, s. 93 i nn., 147-149.

10 Ch. Taylor, op. cit. Warszawa 2001, s. 8-23.

${ }^{11}$ B. Anderson, Wspólnoty wyobrażone: rozważania o źródłach i rozprzestrzenianiu się nacjonalizmu, tłum. S. Amsterdamski, Kraków 1997, s. 19 i nn. 
Rozszerza również tożsamość internautów o poczucie przynależności do cyfrowych wspólnot wirtualnych (np. o poczucie bycia graczem, mieszkańcem e-city, streamerem, awatarem). Podsumowując, edukowani przez literaturę i analogowe techniki kina i telewizji użytkownicy komputerów z łatwością zszywają dziś codzienność ze światów realnych i sztucznych (wyobrażonych, fikcjonalnych, abstrakcyjnych, wirtualnych, projektowanych w rozmaitych tworzywach). Konstytuowane $z$ nich przestrzenie medialne podmiot wykorzystuje pragmatycznie. Włącza je w swoje trwanie i dzieli z innymi, by określić własną jedność i tożsamość z jednej strony, z drugiej zaś - by pracować, integrować się. Podmiot wykorzystuje cyberprzestrzeń, by uczestniczyć w kulturze i życiu, by nie zostać wykluczonym ze współczesności, która mnoży zdalne zadania i kompetencje, a z nimi techniczne procedury identyfikacji oraz zinstytucjonalizawane tożsamości. Na drodze uwewnętrzniania przestrzeni medialnych - ich naturalizowania, udomawiania, narratywizacji - podmiot praktykuje siebie w trosce o własne wielowymiarowe bycie i życie.

\section{O PRAKTYKOWANIU SIEBIE}

Dominująca obecnie wizualność cyfrowa obejmuje reprezentacje przestrzeni zdolne matrycować widzenie rzeczywistości i sposoby jej wizualizowania. Co ważniejsze, integruje wokół nich wspólnoty i dystrybuuje w nich prawo do patrzenia (limitują je systemy policyjne, archiwa rządowe, ekstranet z różnymi zakresami dostępu dla poszczególnych pracowników, dokumenty bez prawa edycji, a nawet etykieta grupy fanów określająca warunki uczestnictwa, hierarchii czy dostęp do archiwalnych fanfictions). Patrzenie daje dostęp do rzeczywistości i konstruowania w niej własnych dyskursów. Prawo do patrzenia to w istocie prawo do rzeczywistości ${ }^{12}$. Pozbawione instytucjonalnie prawa do patrzenia podmioty lub grupy (np. rewolucjoniści, opozycja) czynią środkiem swej ekspresji inne porządki symboliczne (np. wlepki, manifestacje, vlogi) bądź zawłaszczają dominujący porządek obrazowania przy użyciu niejawnych taktyk (np. hakowania, Darknetu, pirackiej telewizji). Alternatywne, podrzędne, równoległe,

${ }_{12}$ N. Mirzoeff, Prawo do patrzenia, tłum. M. Szcześniak, E. Zaremba, [w:] Antropologia kultury wizualnej, red. I. Kurz, P. Kwiatkowska, Ł. Zaremba, Warszawa 2012, s. 738 i nn. 
niejawne narracje i ich współistnienie z dyskursami dominującymi pozwalają wskazać powstające w kulturze przy udziale mediów napięcia. Dotyczy to nie tylko relacji między strategiami i taktykami użytkowania infosfery, z instytucjonalnym podziałem na uprawnionych do głosu i wykluczonych, ale także relacji między wi d z e niem (wizualizowaniem) i kontrwidze n i em (kontrwizualizowaniem) ${ }^{13}$ - czylii między dedykowanym dostępem do budowania i publikowania „obrazów”, wizerunków, a ograniczonym dostępem do mediów. Kontrwidzenie tworzy „kontrobrazy” niepożądane przez dominujący dyskurs i kolportuje je przy udziale innych porządków znakowych i taktyk (zawłaszczania takich jak wpisywanie w uznaną formę rewolucyjnych treści). „Komputer” za sprawą limitowanych i oferowanych użytkownikom przestrzeni dystrybuuje w późnej nowoczesności właśnie prawo do patrzenia. Wyznacza tym samym strategie i taktyki uczestnictwa w kulturze, w tym tryby negocjowania tożsamości (za pomocą narracji, uczestnictwa w przestrzeniach medialnych, sposobów ich użytkowania i kreowania), jej wizualizowania i kontrwizualizowania. Cyberprzestrzeń staje się forum treści kulturowych, polem aktualizacji tradycji i jej międzylub wewnątrzpokoleniowej oceny.

Manuel Castells zaproponował myślenie o uczestnikach cyfrowej komunikacji (i przepływów) w kategoriach tożsamości: legitymizującej, oporu i projektu ${ }^{14}$. Gdy idzie o poczucie przynależności, akces do narodu, zbiorowości, grupy i bycie akceptowanym oraz rozpoznawalnym jako uczestnik danej społeczności - ku czemu służy tożsamość - jednostka wspierająca władzę lub grupę dominującą deklaruje poparcie działań i instytucji władzy. W ten sposób buduje własną jedność. Jednocześnie legitymizuje i umacnia istniejący porządek społeczny i kulturowy (np. budowę społeczeństwa demokratycznego, wojnę w Afganistanie). Jej biegun wyznacza opór (i materializujące go widzenie i wizualizacje, które pozostają w kontrze wobec obrazów powstających w ramach dyskursu dominującego). Tożsamość manifestująca postawy buntu, czy szerzej: oporu, powstaje w opozycji do dyskursu oficjalnego formułowanego przez instytucje i grupy dominujące (np. inne narodowości postrzegające swe państwo jako jednonarodowe, marginalizujące), także w opozycji do dominującego widzenia (wizualizowania,

13 N. Mirzoeff, On Visuality,„Journal of Visual Cultur” 2006, Vol. 5(1), s. 66.

${ }_{14}$ M. Castells, Siła tożsamości, tłum. S. Szymański, Warszawa 2010, s. 22-24. 
obrazów). Jej nośnikiem stają się więc jednostki lub społeczności, które czują się wykluczone, marginalizowane, objęte stygmatyzacją. Efektem ich oporu pozostają narracje alternatywne, konstruowane np. $\mathrm{z}$ własnego dziedzictwa i tradycji, a także formowanie alternatywnych wspólnot. Natomiast autoidentyfikacja projektowa dochodzi do głosu, kiedy na bazie utrwalonych tradycją treści kulturowych konstruowany jest projekt tożsamości. Nowa, a raczej modernizowana tożsamość z reguły redefiniuje pozycję budującej ją zbiorowości i wspiera transformację całej struktury społecznej.

Cyberprzestrzeń daje pole dla postaw tożsamościowych, a zatem praktyk, za którymi stoją techniki siebie. By mogły być realizowane, konieczne są warunki pozwalające dystrybuować w przestrzeniach mediów prawo do patrzenia, prawo do rzeczywistości (jej widzenia i wizualizowania). Digitalna Ziemia deklaruje wolność, równość i braterstwo uczestników zbiorowej inteligencji ery globalnej. Prawo udziału w tej zbiorowości przysługuje nominalne każdemu, podobnie niczym wolność wypowiedzi - legitymizujących, niosą opór lub projekt przewartościowania tradycji i współnoty. Wymogiem algorytmicznego kapitalizmu pozostaje kreatywność, a nie parezja ${ }^{15}$. Bycie kreatywnym ma dziś identyfikować nie postfordowską elitę wiązaną zasięgiem technologii, lecz modelowego uczestnika kultury - (po) nowoczesną osobę, która przy użyciu mediów na drodze troski o siebie za model wymiany i kontaktu $\mathrm{z}$ innymi przyjmuje działania public relations, komunikację i zarządzanie sobą przy udziale wizerunku (a ściślej: wizerunków). Modelowa tożsamość zyskuje w globalistycznych retorykach zasięg uniwersalny. Popularyzowany wzór jednostki, uczestniczącej w rzeczywistości dzięki umiejętności obsługi „komputera”, w praktyce kultury zyskuje alternatywy. Podrzędne, wykluczone, nieobecne w dyskursie oficjalnym tożsamości, tworzywa, narracje i taktyki korzystania z przestrzeni wymagają gruntownego opracowania w kontekście zbiorowych tożsamości wspólnot realnych, wyobrażonych, a także wirtualnych. Jednak nawet skreślone w postaci powyższego szkicu odsłaniają przebieg trwającej zmiany kulturowej, a wraz z nią faktyczną dystrybucję prawa do widzenia, jaką w skali globu funduje „komputer” lansowany przez retoryki globalizacji jako uniwersalne narzędzie ludzkości.

15 M. Foucault, Rządzenie sobą $i$ innymi, tłum. M. Herer, Warszawa 2018, s. 59-78. 
Ideologie globalnego „cyberkontynentu”, „cyberziemi”, w manifestach gwarantują swoim udziałowcom dostęp do rzeczywistości podanej w obrazach oraz do tworzenia obrazów. Ponowoczesne poznanie i troska o siebie - sensu stricto patrzenie i tworzenie - są realizowane pod okiem technologii wizualnego nadzoru (np. administratora portalu, policji). Obecnie kontrola przekroczyła formułę oka nadzorcy niewolników, a nawet fabrycznych kamer lat trzydziestych i monitoringu klientów Best Mallu, by sięgać po satelitarne geolokacje, profile użytkownika, algorytmy decyzji i inne cyfrowe identyfikatory, znaki jednostki. Produktem ich pracy są obrazy - „My”, użytkownicy ewidencjonowani jako obrazy, wizualizacje wyrażone w jednostkach pomiaru, jakimi operują aktualne technologie nadzoru i które w podręcznikach marketingu definiują tożsamość klienta, użytkownika mediów lub członka organizacji. Przy ich udziale późna nowoczesność jest naturalizowana $w$ roli przestrzeni otwartej na życie człowieka: jego praktyczne działania, jednostkowe aksjologie, akty poznania, emocji, woli. Narrację dominującą, która oferuje współczesność jako świat egzystencji i trwania jednostek integrowanych wokół technologii, za Lefebvr'em i Mirzoeffem trzeba uznać za fakt społeczny i kulturowy, który należy określić mianem wizualności (i porządkiem wizualizowania). W jej ramach podmiot legitymizujący władzę z powodzeniem odnajdzie elementy, z których zdoła zbudować swoją wewnętrzną spójność i które umożliwią integrację z grupą. Narracje podrzędne, równoległe w polu cyfrowej wizualności będą wspierać (np. w Darknecie lub na ulicy) inne futurologiczne lub wcześniejsze niż instytucjonalizowane przez algorytmiczny kapitalizm wizerunki świata i kreatywnego człowieka. Istota tego procesu tkwi w kompletowaniu dominującego porządku wizualizowania i materializacji kontrwidzenia i kontrobrazowania.

„Komputer” wytworzył porządki przestrzeni i określił definiowane powyżej za Michelem de Certeau sposoby ich cielesnego praktykowania. Za sprawą cybermiejsc i hybryd onto-ontologicznych postawił użytkownika mediasfery w sytuacji permanentnego kreowania własnej rozpoznawalności i własnych wizerunków (w ramach wizualizowania i kontrwizualizowania). Jednakże podmiot budujący w trosce o siebie kolejne medialne tożsamości w istocie „wykorzystuje złudzenie nie jedności, ale nieskończonego 
mnożenia masek"16. W cyberprzestrzeni to nie jednostka wpisana w kulturowe wzorce, role społeczne i etyczne wybory podlega identyfikacji, lecz właśnie maski. Pomimo deklaracji globalistów i speców od marketingu maszyny tworzą nie tożsamości, a jedynie maski. Rozpoznają jednostkę metrycznie, wizualizują ją w oparciu o ujednolicone matematycznie dane. Wówczas podmiot zyskuje „tożsamość” - maskę cyfrową, stworzoną dzięki identyfikacji oka czy odcisku palca, algorytmowi konsumenta, listy wizytowanych stron i aplikacji, wpisów, zdjęć na Instagramie. Jego aktywności są wizualizowane narzędziami Google czy Microsoft, a przez firmy dostarczające technologie są gromadzone, a także kontrolowane i projektowane w postaci baz danych. Maszyny tworzą obraz jednostki z informacji dotyczących jej aktywności odnotowanej w cyberprzestrzeni w postaci spersanolizowanych algorytmów. Pozwalają one kontrolować użytkowników cyberprzestrzeni i apelować do nich za pośrednictwem obrazów krojonych wedle ich matematycznie opracowanych preferencji (profili użytkownika). Pomagają zyskiwać ich przychylność w ramach marketingowych strategii „echa” i „lustra”. Wykorzystują je zarówno firmy sprzedające buty, jak i sztaby wyborcze, które włączają do swych internetowych reklam obrazy i treści wyszukiwane wcześniej w Internecie przez potencjalnych nabywców obuwia i elektorat. (Przykład stanowi kampania Donalda Trampa, który prowadzenie kampanii prezydenckiej w mediach społecznościowych oparł na algorytmach internautów dostarczonych przez firmę Google.) Przed globalistyczną standaryzacją doby postmediów podmiot także chroni się za maskami. W trosce o siebie przyjmuje tożsamość kameleona. Daje odpór „nadzorcom” w podziemiu internetowym: aktualizuje osobę „rycerza” i przyjmuje rolę hakera lub cyberterorysty, który korzysta z mediów, by walczyć w imię internautów lub religii. Quasi-tożsamości, profile, szyte z algorytmów maski instytucjonalne i konsumenckie, maski taktyczne wyrosłe z troski o siebie, przesłaniające tożsamość, cele i intencje podmiotu, zmieniane tytułem gry i zabawy, ochrony maski ludyczne - wszystkie wciąż waloryzują treści kulturowe kontekstu. Bez względu na to, czy idzie o taktyki, czy o strategie, w mediasferze wcielenia grupy i jednostki ustawicznie podlegają aktom symulacji i replikowaniu. Manifestowana tożsamość za sprawą cybertechnologii zy-

${ }^{16}$ G. Agamben, Tożsamość bez osoby, tłum. K. Żaboklicki, [w:] idem, Nagość, Warszawa 2010, s. 64. 
skuje postać potencjalnie mnogą. O jej zmienności i ambiwalencji przesądza aktualna szybkość cyfrowego transferu danych; algorytm zaś decyduje o jej atrakcyjności rynkowej, ustalanej w oparciu o obrazy (treści) wiązane z nią lajkami i linkami (stron np. wyborczych, sklepów, produktów, obrazów umieszonych na takich portalach, jak Facebook czy Instagram etc.). Za sprawą algorytmów, wskaźników parametrycznych, obrazów, wskaźników popularności jednostka otaczana jest w mediasferze bańką nie tylko kontroli, ale i informacji. Strategie mediów i taktyki ich użytkowników zmieniają się i wymagają nieprzerwanego badania. Jednakże każda budowana w oparciu o narzędzia rozwiniętej audiowizji tożsamość zyskuje wymiar, potencjał i stan, które proponuję określić mianem tożsamości wielokrotnej.

Podążająca tropem tożsamości, widzenia i kontrwidzenia antropologia mediów staje się dziś koniecznością. Ponowoczesność bowiem przyniosła nadprodukcję przestrzeni wytwarzanych przez maszyny, a globalizacja algorytmiczna i postwzrostowa - wciąż napędza ich produkcję w postaci medialnych światów, alternatywnych środowisk, masek, tożsamości wielokrotnych. Liczba przepływów informacji i niejawnych transferów danych ${ }^{17}$, życie w przestrzeni rozszerzonej o sztuczne obiekty i zdarzenia, sytuacyjna zmienność rzeczywistości warunkowana prędkością transmisji danych i wyborami użytkownika (np. smartfona), a także brak jednorodności ontycznej - wszystkie te zjawiska wymagają nie tylko analizy sposobów uczestnictwa w mediach, w kulturze, ale także stałego kreślenia map, aktualizacji zjawisk medialnych, generowania problemów i pojęć.

\section{Bibliografia}

Giorgio Agamben, Tożsamość bez osoby, tłum. K. Żaboklicki, [w:] idem, Nagość, WAB, Warszawa 2010.

Benedict Anderson, Wspólnoty wyobrażone: rozważania o źródłach i rozprzestrzenianiu się nacjonalizmu, tłum. S. Amsterdamski, Znak, Kraków 1997.

Karina Banaszkiewicz, Audiowizualność i mimetyki przestrzeni, Oficyna Naukowa, Warszawa 2011.

Manuel Castells, Społeczeństwo sieci, tłum. M. Maroda i in., PWN, Warszawa 2007. Manuel Castells, Siła tożsamości, tłum. S. Szymański, PWN, Warszawa 2010.

17 M. Castells, Społeczeństwo sieci, tłum. M. Maroda i in., Warszawa 2007, s. 411-417. Zob. również: R. Debray, Transmettre, Paris 1977. 
Manuel Castells, Wynaleźć codzienność. Sztuki działania, tłum. K. Thiel-Jańczuk, Wydawnictwo UJ, Kraków 2008.

Régis Debray, Transmettre, Édition Odil Jacob, Paris 1977.

Michel Foucault, Inne przestrzenie, tłum. A. Rejniak-Majewska, „Teksty Drugie” 2005, nr 6(96).

Michel Foucault, Techniki siebie, tłum. D. Leszczyński, L. Rasiński, [w:] idem, Filozofia, historia, polityka. Wybór pism, PWN, Warszawa-Wrocław 2000.

Michel Foucault, Rządzenie soba $i$ innymi, tłum. M. Herer, PWN, Warszawa 2018.

Martin Heidegger, Bycie i czas, tłum. B. Baran, PWN, Warszawa 2004.

Henri Lefebvre, Production de l'espace, Anthropos, Paris 2000.

Lew Manovich, Poetyka powiększonej przestrzeni, tłum. A. Nacher, [w:] Miasto sztuki -sztuka miasta, red. E. Rewers, Universitas, Kraków 2010.

Nicholas Mirzoeff, Prawo do patrzenia, tłum. M. Szcześniak, Ł. Zaremba, [w:] Antropologia kultury wizualnej, red. I. Kurz, P. Kwiatkowska, Ł. Zaremba, Wydawnictwo UW, Warszawa 2012.

Nicholas Mirzoeff, On Visuality, „Journal of Visual Cultur” 2006, Vol. 5(1).

Charles Taylor, Źródła podmiotowości. Narodziny tożsamości nowoczesnej, tłum.

M. Gruszczyński, PWN, Warszawa 2001.

\section{Practicing Media/Practicing Oneself... On Experiencing the Space of Late Modernity}

In advanced globalization, the digital code, computer, and Internet become tools of cultural change. 2-3-4.0 generation media produce images, artificial events, objects, as well as methods of vision prevailing in design, design processes, and communication. The number of visibility types offered to users, results in media matrices becoming regimes of (for) the eye, of (for) a bodily experience. It also shapes a sense of reality by means of media space (TV stream, cyberspace) and spaces inscribed in media forms (simulations, hybrids, onto-ontological topias). Two issues seem of particular relevance here. Questions about access to reality offered by 'images' (satellites, HDMI helmets, combat glasses, etc.) and possibilities of seeing the world from behind the visual media matrices.

Media, multi-media communication platforms distribute not only schemes of viewing, but also the right to look (extranet, friends lists, access to archives and libraries, consumer profiles collected by Google, MS, etc.). The excess of artificial forms and spaces, on the other hand, directs attention to participation and participants of culture: individuals and communities (real, imagined, virtual). Their activities in cyberspace, including identity and identity practices, should be the focus of interest. The author of the text reflects upon identity practices of the 
individual, that is the individual's participation in culture through the prism of immaterial materiality, self-care, and the need for bonds and integration with the Others. She discusses techniques of advanced audio-vision (their matrices and spatiality), as well as creation of subjective coherence negotiated with others in terms of individual - group (conventional) - universal content (e.g. humanity). Identity practices are located within the framework of data flows and transmissions, information bubbles, heterotopia, and identities of legitimization, resistance, and design implemented there. The author of the text also perceives identity from the perspective of a person and a mask, of users' tactics articulating their presence in cyber-virtual communities (e.g. avatars, nicks, multiple identities), as well as in the perspective of data visualization: user profiles, metric identifiers, files, selection algorithms, search history, archives of published photos..., in other words institutional (cyber)surveillance strategies.

Keywords: order of viewing, visualize/counter visualize, cyberspace, media hybrids, identity, algorithmic capitalism, technologies of the Self

Data otrzymania tekstu: 11.12.2020 r.

Data zakończenia procesu recenzyjnego: 3.02.2021 r.

Data akceptacji tekstu do druku: 8.02.2021 r. 
